\title{
Efficacy of Intravenous Paracetamol Infusion Versus Intramuscular Tramadol as an Intrapartum Labour Analgesia
}

\author{
Abida Rehman, ${ }^{1}$ Arshea Maryam, ${ }^{1}$ Noreen Nasim, ${ }^{1}$ Riaz Hussain, ${ }^{2}$ Moeen Akhtar Malik ${ }^{3}$
}

\begin{abstract}
Background: Various studies have debated intravenous paracetamol as analgesic agent. However, there are no significant trials regarding comparison of paracetamol with other agents like Tramadol regarding analgesic effect on labor pain.

Objective: To compare the efficacy of intravenous paracetamol infusion versus intramuscular tramadol as an intrapartum labour analgesia.

Methodology: In this quasi experimental study, a total of 110 women with active phase of labour of term pregnancy, 18 to 40 years of age, were included. Duration and setting: May to November, 2019 at Department of Obstetrics and Gynaecology, Shaikh Zayed Hospital Rahim Yar Khan. In Group A, single $100 \mathrm{ml}$ intravenous infusion containing $1000 \mathrm{mg}$ of paracetamol while in Group B patients, tramadol hydrochloride $100 \mathrm{mg}$ intramuscular, was given. All patients in both groups were evaluated by visual analogue scale and efficacy (yes/no) was noted. SPSS 20 was used for data analysis.

Results: The mean age of women in group A was $27.73 \pm 5.35$ years and in group B was $27.36 \pm 5.61$ years. The mean gestational age in group A was $39 \pm 1.53$ weeks and in group B was $38.95 \pm 1.56$ weeks. Parity was from 0 to 5 with mean parity of $2.46 \pm 1.17$. Efficacy (in terms of VAS score 0-3) was seen in 21 (38.18\%) in group A (intravenous paracetamol infusion) and $09(16.36 \%)$ in group B (intramuscular tramadol) with p-value of 0.010 .

Conclusion: This study concluded that efficacy of intravenous paracetamol infusion is better than intramuscular tramadol as an intrapartum labour analgesia.
\end{abstract}

Key words: Intrapartum labour analgesia, Intravenous paracetamol infusion, Intramuscular tramadol

Article Citation: Rehman A, M Arshea, Nasim N, Hussain R, Malik MA. Perception of females regarding gender based violence. JSZMC 2020;11(1):22-26

\section{Introduction}

Labor pain is among the most unbearable pain experienced by women and it may affect maternal psychology and course of labor causing apprehension, anxiety and stress. ${ }^{1}$ Pain during the first stage of labor originates predominantly due to cervical dilatation and uterine muscle wall ischemia leading to lactate accumulation. ${ }^{1}$ During the late first stage and second stage of labor, the vagina and perineum form additional sources of pain. ${ }^{2}$ The associated increase in sympathetic activity leads to increased oxygen consumption, respiratory alkalosis, and metabolic acidosis which could lead to decreased oxygen being transferred to the fetus. Thus, pain relief during labor is expected to reduce maternal stress and improve maternal and perinatal outcome. ${ }^{3}$

Advances in the field of labour analgesia have travelled long journey from the days of ether and chloroform to the present day practice of comprehensive program of labour pain management using evidence based medicine with regional analgesia being gold standard nowadays and routinely used in developed countries. ${ }^{4}$ But most modern obstetric analgesic practices require the participation of expert anaesthesiologist, costly equipment and continuous monitoring facilities, which unfortunately cannot be availed in routine obstetric practice in the developing countries, where a majority of obstetric services are in the hands of trained nurses and non-specialist doctors. Here comes into picture, the drugs like paracetamol and opiods like tramadol hydrochloride in the field of labour analgesia, especially in the developing countries.

Various studies have proved intravenous paracetamol as effective analgesic agent which is safe, effective, inexpensive, and requires no special

1.Department of Obstetrics \& Gynecology, Sheikh Zayed Medical College/Hospital, Rahim Yar Khan, University of Health Sciences, Lahore, Pakistan.

2.Department of General Surgery, Sheikh Zayed Medical College/Hospital, Rahim Yar Khan, University of Health Sciences, Lahore, Pakistan.

3.Department of Medicine, Sheikh Zayed Medical College/Hospital, Rahim Yar Khan, University of Health Sciences, Lahore, Pakistan.

Correspondence: Dr. Abida Rehman, Associate Professor, Department of Obstetrics \& Gynecology,

Sheikh Zayed Medical College/Hospital, Rahim Yar Khan, Pakistan

Received: 26-11-2019 Reviewed: $15-12-2019$ 
monitoring. However, there are no significant trials regarding paracetamol analgesic effect on labor pain in women. ${ }^{6}$ Tramadol hydrochloride is acentrally acting analgesic opioid. Intramuscular tramadol hydrochloride is commonly used in labor analgesia in developing countries as it is inexpensive; no special monitoring is required and has been widely studied and proved for its safety and efficacy in labor analgesia. ${ }^{7}$ In some previous studies, after 3 hours of administration, efficacy (no or mild pain) in paracetamol group and in tramadol group, mixed pattern of results were reported. ${ }^{8,9}$ As previous studies have shown the varying efficacy of paracetamol and tramadol in intrapartum labour analgesia, so, there is need of a study to re-evaluate better drug among these two. Moreover, no local study available on this aspect, so we decided to conduct this study to compare the efficacy of intravenous paracetamol infusion versus intramuscular tramadol as an intrapartum labour analgesia in our study setting. This study may provide us the local statistics but also based on this empirical evidence, laboring women can be provided with a more efficacious intrapartum labour analgesic for reducing labour pain in women in order to reduce perinatal mortality and morbidity of both mother and fetus.

\section{Methodology}

This quasi experimental study, of six months duration was conducted from May to November, 2019 at Department of Obstetrics and Gynaecology Unit I, Sheikh Zayed Medical College/Hospital, Rahim Yar Khan. A total of 110 women, aged 18-40 years with singleton pregnancy and gestational age 37-41 weeks, having parity $0-4$, were included in the study using nonprobability consecutive sampling. Women with history of diabetes mellitus, preeclampsia, hypersensitive to both drugs and women with antepartum hemorrhage, women with severe intrauterine growth retardation $(<2.5 \mathrm{~kg}$ weight $)$ were excluded from the study.

Study was started after approval from local ethical committee. Informed, written consent was taken from each patient. All patients were divided in two equal groups (A and B) by lottery method. In Group A, single $100 \mathrm{ml}$ intravenous infusion containing $1000 \mathrm{mg}$ of paracetamol single dose over 15 minutes, was given while in Group B, tramadol hydrochloride $100 \mathrm{mg}$ intramuscular single dose in upper and outer quadrant of gluteal region with a $2 \mathrm{ml}$ syringe was given. All patients in both groups were evaluated till 3 hours by visual analogue scale (VAS) and efficacy (yes/no) was noted as "yes" if VAS score was $0-3$, otherwise it was deemed as "no". All data including the demographic data (age, gestational age, parity, BMI) was recorded on a predesigned proforma. Mean and standard deviation were calculated for age, gestational age and BMI. Qualitative variables like parity and efficacy of drugs in both groups was presented as frequency and percentage. Chi-square test was applied to compare efficacy in both groups taking $p$-value $\leq 0.05$ as significant. Effect modifiers like age, gestational age, parity and BMI, were controlled by stratification.

\section{Results}

Age range in this study was from 18 to 40 years. The mean age of women was $27.73 \pm 5.35$ versus $27.36 \pm$ 5.61 years in group A and group B respectively. Gestational age was from 37 to 41 weeks. Mean gestational age in group A was $39 \pm 1.53$ weeks and in group B was $38.95 \pm 1.56$ weeks. Mean BMI was $28.80 \pm 3.12$ versus $29.82 \pm 3.21 \mathrm{~kg} / \mathrm{m}^{2}$ in Group A and $\mathrm{B}$ respectively.

There were $29(52.73 \%)$ versus $28(50.91 \%)$ patients of the age 18-30 years in Group A and B while 26 $(47.27 \%)$ versus $27(49.09 \%)$ patients of the age of 31-40 years in Group A and B respectively. There were $32(58.18 \%)$ versus $33(60 \%)$ patients having gestational age 37-39 weeks in Group A and B while $23(41.82 \%)$ versus $22(40.0 \%)$ patients having gestational age 40-41weeks in Group A and B respectively.

\section{Figure I: Efficacy of Intravenous Paracetamol versus Intramuscular Tramadol among Women in Labour}

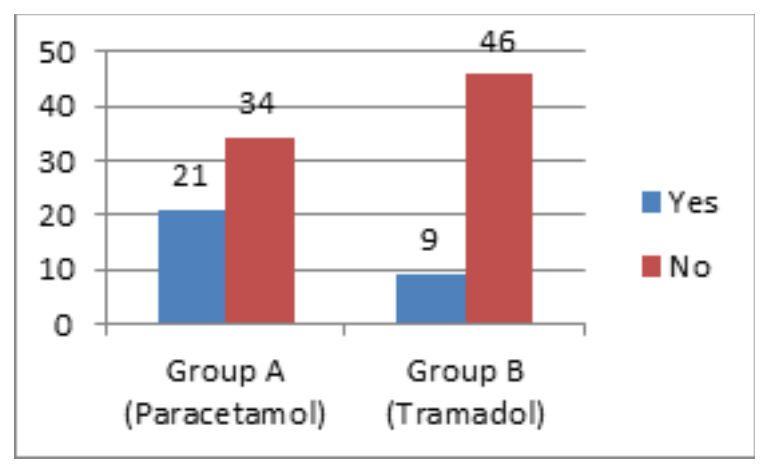


There were $22(40 \%)$ versus $14(25.45 \%)$ patients having $\mathrm{BMI} \leq 27 \mathrm{~kg} / \mathrm{m}^{2}$ in Group A and B whereas $33(60.0 \%)$ versus $41(74.55 \%)$ patients having BMI $>27 \mathrm{~kg} / \mathrm{m}^{2}$ in Group A and B respectively. There were $30(54.55 \%)$ versus 31 (56.36\%) patients having parity $0-2$ in Group $A$ and B while $25(45.45 \%)$ versus $24(43.64 \%)$ patients having parity 3-4 in Group A and B respectively.

Efficacy was seen in 21 patients $(38.18 \%)$ in group A (intravenous paracetamol infusion) and 9 patients $(16.36 \%)$ in group B (intramuscular tramadol) with p-value of 0.0101 as shown in figure I. Stratification of age, parity, gestational age and BMI of patients according to efficacy is shown in Table I.

Table I: Efficacy versus Age, Parity, Gestational age, BMI in both Groups.

\begin{tabular}{|c|c|c|c|c|c|}
\hline \multirow{3}{*}{ Variable } & \multicolumn{2}{|c|}{ Group A } & \multicolumn{2}{|c|}{ Group B } & \multirow[t]{3}{*}{ P value } \\
\hline & \multicolumn{2}{|c|}{ Efficacy } & \multicolumn{2}{|c|}{ Efficacy } & \\
\hline & Yes & No & Yes & No & \\
\hline \multicolumn{6}{|c|}{ Age (in Years) } \\
\hline $18-30$ & 11 & 18 & 03 & 25 & 0.01 \\
\hline $31-40$ & 10 & 16 & 06 & 21 & 0.19 \\
\hline Total & 21 & 34 & 9 & 46 & \\
\hline \multicolumn{6}{|l|}{ Parity } \\
\hline $0-2$ & 12 & 18 & 04 & 27 & 0.01 \\
\hline $3-4$ & 09 & 16 & 05 & 19 & 0.24 \\
\hline Total & 21 & 34 & 9 & 46 & \\
\hline \multicolumn{6}{|c|}{ Gestational Age (in Weeks) } \\
\hline $37-39$ & 13 & 19 & 08 & 25 & 0.15 \\
\hline $41-41$ & 08 & 15 & 01 & 21 & 0.02 \\
\hline Total & 21 & 34 & 9 & 46 & \\
\hline \multicolumn{6}{|c|}{ BMI (in $\left.\mathrm{Kg} / \mathrm{m}^{2}\right)$} \\
\hline$=27$ & 08 & 14 & 01 & 13 & 0.11 \\
\hline$>27$ & 13 & 20 & 08 & 33 & 0.05 \\
\hline Total & 21 & 34 & 9 & 46 & \\
\hline
\end{tabular}

\section{Discussion}

Labour is generally considered to be a painful experience and analgesia is regularly required. In a study comparing different painful medical conditions, the average labour pain scores in primigravid and multigravid women were more than that of sciatic, dental or bone fracture pain scores. ${ }^{10,11}$ Possible causes of labour pain may include stretch of the cervix during dilatation, ischaemia of the muscle wall of the uterus with buildup of lactate and stretch of the vagina and perineum in the second stage. ${ }^{12-14}$ Thus, pain relief during labor is expected to reduce maternal stress and improve maternal and perinatal outcome. Obstetric analgesia and anesthesia have evolved from vague possibility to reality. The non-pharmacological techniques of analgesia include emotional support, relaxed birth environment, psycho-somatic preparation, yoga, acupuncture, and transcutaneous electrical nerve stimulation (TENS). The commonly used and more effective are pharmacological techniques include opioids like pethidine and tramadol though the regional analgesia is gold standard nowadays and routinely used in modern obstetric anesthesia in developed countries. The newer advances like combined spinal epidurals, low dose epidurals, patient-controlled intravenous, inhalational, and epidural analgesia have revolutionized obstetric anesthesia. ${ }^{15}$ We have conducted this study to compare the efficacy of intravenous paracetamol infusion versus intramuscular tramadol as an intrapartum labour analgesia. The mean age of women was $27.73 \pm 5.35$ versus $27.36 \pm 5.61$ years in group A and group B. Majority of the patients $57(51.82 \%)$ were between 18 to 30 years of age. Efficacy was seen in 21 (38.18\%) patients in group A (intravenous paracetamol infusion) and $09(16.36 \%)$ in group B (intramuscular tramadol) with p-value of 0.01 .

Our study results are comparable with available literature. In a study, after 3 hours of administration, efficacy (no or mild pain) in paracetamol group was seen in $2.04 \%$ women while in tramadol group, it was seen in only $15.30 \%$ women.

Aimakhu et $\mathrm{al}^{16}$ comparing paracetamol with tramadol revealed in their study that after the administration of first rescue dose, there was no significant difference in the mean pain score in both groups at recruitment, 30 minutes, 60 minutes post rescue dose, and 120 minutes postpartum. However, at 120 minutes, 180 minutes post rescue dose, and 60 minutes postpartum, an obvious increase was observed in the mean pain scores of those in paracetamol group. Although, this difference was not statistically significant ( $\mathrm{p}$-values $=0.36,0.06$, and 0.10 , respectively). Out of the 142 participants, only $32(22.5 \%)$ expressed their dissatisfaction to the trial drug, out of which18 (25.4\%) were in tramadol group as against $14(19.7 \%)$ in paracetamol group. About half of the respondents, $65(45.8 \%)$ were satisfied out 
of which $35(49.3 \%)$ were in paracetamol group and $30(42.3 \%)$ were in tramadol group. Forty five parturients were slightly satisfied with trial drug; $22(31.0 \%)$ were in paracetamol group while 23 $(32.4 \%)$ were in tramadol group. The difference in satisfaction between the two trial drugs was however not significant $\left(\chi^{2}=0.91, \mathrm{p}\right.$-value $\left.=0.64\right)$. Another study comparing the effectiveness of paracetamol to pethidine in labor conducted in Iran concluded that intravenous paracetamol is more effective than intramuscular pethidine to relieve labor pain in normal vaginal delivery. ${ }^{6}$ These two studies show the effectiveness and safety of paracetamol as labor analgesia.

A number of studies have suggested that paracetamol is an effective treatment for postoperative pain relief. ${ }^{17,18}$ Studies examining analgesic effect of paracetamol in obstetrics surgeries such as abortion, ${ }^{19}$ postoperative pain after cesarean delivery, ${ }^{20,21}$ and perineal pain after child birth $^{22,23}$ have proposed that paracetamol has an admirable analgesic effect; however, there are limited clinical trials regarding paracetamol analgesic effect on labor pain.

Meenakshi $\mathrm{L}$ et $\mathrm{al}^{1}$ suggested that intravenous paracetamol is more effective labour analgesic with fewer maternal adverse effects and shortens labour as compared to intramuscular tramadol. Paracetamol also shortens the length of labour and has fewer maternal adverse effects than tramadol. Fetal outcome of both drugs are favourable. In a prospective, observational and clinically randomized study ${ }^{24}$ conducted in the labor room of the department of Obstetrics and Gynaecology/ Govt. Medical College Rajindra Hospital, Patiala, Punjab. A total of 200 pregnant women were included in study after fulfilling inclusion criteria. These women were divided into 2 group of 100 each. Group A received a $100 \mathrm{ml}$ intravenous infusion containing $1000 \mathrm{mg}$ paracetamol single dose over $15 \mathrm{~min}$. Group B received intramuscular tramadol hydrochloride 100mg single dose. Pain intensity of women with both drugs was noted before administration of drug, one hour and three hours after administration of drug using McGills Pain intensity scale. No difference in pain intensity is seen before drug administration. After 1 hour of drug administration, in paracetamol group, $6.3 \%$ women had horrible pain, and 29.5\% had distressing pain, while in tramadol group, $28.6 \%$ women had horrible pain, and $57.1 \%$ had distressing pain. After 3 hour of drug administration in paracetamol group, $23.2 \%$ had distressing pain, while in tramadol group, $46.9 \%$ women faced horrible pain, and $32.7 \%$ had distressing pain. Labor duration in paracetamol and tramadol group was 5.2 and 5.6 hour, respectively. In paracetamol group, nausea is seen in 6\%and vomiting in $3 \%$, while in tramadol group, nausea is seen in $8 \%$ and vomiting in $7 \%$. Hema Mohan et $\mathrm{al}^{8}$ evaluated used of intravenous paracetamol infusion versus intramuscular tramadol as an intrapartum labor analgesic. They was no difference in pain intensity seen before drug administration. After 1 hour of drug administration, in paracetamol group, 4\% women had horrible pain, and $28 \%$ had distressing pain, while in tramadol group, $30 \%$ women had horrible pain, and $60 \%$ had distressing pain. After 3 hours of drug administration, in paracetamol group, 26\% had distressing pain, while in tramadol group, $50 \%$ women had horrible pain, and 36\% had distressing pain. Labor duration in paracetamol and tramadol group was 4.6 and 6 hours, respectively. In paracetamol group, nausea was seen in $2.2 \%$ and vomiting in $1.1 \%$, while in tramadol group, nausea was seen in $6.4 \%$ and vomiting in $4.3 \%$. They concluded that intravenous paracetamol is more effective labor analgesic with fewer maternal adverse effects and shortens labor as compared to intramuscular tramadol.

NehaGarg and Vanitha $\mathrm{VG}^{25}$ while comparing intravenous paracetamol and intravenous tramadol for labour analgesia found that mean VAS score decreased significantly to a greater extent in group $\mathrm{P}$ $(100 \mathrm{ml}$ intravenous infusion containing 1 gram of paracetamol single dose) than group $\mathrm{T}$ (100 $\mathrm{mg}$ of tramadol hydrochloride diluted in $100 \mathrm{ml}$ normal saline) and showed a significant statistical difference among both the groups $(\mathrm{p}<0.001)$. In both the groups, the difference in the VAS score was statistically significant $(p<0.05)$. The duration of labour was statistically shorter in group $\mathrm{P}(\mathrm{p}<$ $0.0001)$. The participants in group $\mathrm{T}$ had more incidence of maternal side-effects and 7 NICU admission than in paracetamol group. They concluded that Intravenous paracetamol has better analgesic efficacy, shorter duration of labour and fewer maternal side effects and is a more effective labour analgesic than tramadol. Jeetinder Kaur Makkar et $\mathrm{al}^{5}$ concluded intravenous paracetamol provides comparable analgesia as intramuscular tramadol during active labour. Abinaya $\mathrm{A}$ et $\mathrm{al}^{26}$ 
found no difference in pain intensity that was visible earlier than drug administration. There was significant pain reduction after 1 and 3 hours of paracetamol administration compared to tramadol. Total duration of labour from enrolment in study to delivery in the paracetamol group changed was 276 minutes (4 hrs 36 minutes) \pm 59.97 minutes and in the tramadol group it was 393 minutes (6hrs 33 minutes) \pm 74 minutes which concluded duration of labour was shortened in paracetamol group. In the paracetamol group, nausea was seen in $6.67 \%$ accompanied by vomiting $(3.33 \%)$. Nausea became most commonest side effect in the tramadol group $(13.3 \%)$ followed by vomiting (10\%). APGAR scores in both groups had been satisfactory. They concluded that intravenous paracetamol was more effective labour analgesic with fewer maternal side effects and shortens labour in comparison to intramuscular tramadol.

\section{Conclusion}

This study concluded that efficacy of intravenous paracetamol infusion is better than intramuscular tramadol as an intrapartumlabour analgesia. Therefore we recommend that intravenous paracetamol infusion should be encouraged in our routine practice as an intrapartum labour analgesia for reducing labour pain in women in order to reduce perinatal mortality and morbidity of both mother and fetus.

Authors Contribution: AR: Conception and Design of Work and Revising. AM: Design of Work and Interpretation of Data. NN: Interpretation of Data and revising. SG: Analysis of data and drafting. RH: Conception and Design of Work and Revising. MAM: Conception of work, interpretation of data and revising.

All the authors gave final approval for publication and agreed to be accountable for all aspect of work.

\section{Conflict of Interest: None Sources of Funding: Self}

\section{References}

1. Lallar M, Anam H, Nandal R, Singh SP, Katyal S. Intravenous paracetamol infusion versus intramuscular tramadol as an intrapartum labor analgesic. J Obstet Gynaecol India 2015; 65(1): 17-22.
2. Rani SS. Role of tramadol in labor analgesia. Sch J App Med Sci 2015; 3(6C): 2347-50.

3. Elbohoty AE, Abd-Elrazek H, Abd-El-Gawad M. Intravenous infusion of paracetamol versus intravenous pethidine as an intrapartum analgesic in the first stage of labor. Int J Gynaecol Obstet 2012;118:7-10.

4. Elbohoty AEH. Intravenous infusion of paracetamol versus intravenous pethidine as an intrapartum. Int $\mathrm{J}$ Gynecol Obstet 2012; 118: 7-10.

5. Makkar J, Jain K, Bhatia N, Jain V, Mal Mithrawal S. Comparison of analgesic efficacy of paracetamol and tramadol for pain relief in active labor. J Clin Anesth 2015; 27(2): 159-63.

6. Abdollahi MH, Mojibian M, Pishgahi A, Mallah F, Dareshiri S, Mohammadi S. Intravenous paracetamol versus intramuscular pethidine in relief of labor pain in primigravida women. Niger Med J 2014; 54: 55-7.

7. Patil S, Somashekara SC, Goud GK. Tramadol analgesia in labour. Int J Pharm Biomed Res 2012; 3(1): 49-51.

8. Mohan H, Ramappa R, Sandesh M, Akash BK. Intravenous paracetamol infusion versus intramuscular tramadol as an intrapartum labor analgesic. Int J Reprod Contracept Obstet Gynecol 2015; 4: 1726-29.

9. Das BP, Ali J, Baruah A. Comparative study between intravenous paracetamol and intramuscular tramadol as labour analgesic. Int J Sci Res 2016; 5(10): 1675-79.

10. Nezhad HS, Aram S, Monajjemi Z, Jaafar-Zadeh L. Intravenous fentanyl infusion as an analagesic agents for labor pain. J Res Med Sci 2001; 6: 1-2.

11. Tournaire M, Theau-Yonneau A. Complementary and alternative approaches to pain relief during labor. Evid Based Complement Alternat Med 2007; 4: 409-17.

12. Allameh Z, Rouholamin S, Hekmat R. Comparison of vaginal misoprostol tablet with oxytocin infusion for induction of labor in term pregnancy. J Res Med Sci 2012; 17: 134-9.

13. Brennan D. The ABC of child care politics. Aust J Soc Issues 2007; 42: 213.

14. Zahiri Soroori Z, Hajar Sharami S, Heidarzadeh A, Shokri L. The comparison between suppository diclofenac and pethidine in post-cesarean section pain relief: A randomized controlled clinical trial. J Res Med Sci 2006; 11:292-6.

15. Pandya ST. Labour analgesia: recent advances. Indian $\mathbf{J}$ Anaesth 2010; 54(5): 400-8.

16. Aimakhu CO, Saanu OO, Olayemi O. Pain relief in labor: A randomized controlled trial comparing intramuscular tramadol with intramuscular paracetamol at the University College Hospital, Ibadan, Nigeria. Trop J Obstet Gynaecol 2017;34: 91-8.

17. Moore A, Collins S, Carroll D, McQuay H, Edwards J. Single dose paracetamol (acetaminophen), with and without codeine, for postoperative pain. Cochrane Database Syst Rev 2000; 2: Cd001547.

18. Tzortzopoulou A, McNicol ED, Cepeda MS, Francia M, Farhat T, Schumann R. Single dose intravenous propacetamol or intravenous paracetamol for postoperative pain. Cochrane Database Syst Rev 2011; 5: Cd007126.

19. Penney G. Treatment of pain during medical abortion. Contraception 2006; 74: 45-7. 
20. Alhashemi JA, Alotaibi QA, Mashaat MS, Kaid TM, Mujallid RH, Kaki AM. Intravenous acetaminophen vs oral ibuprofen in combination with morphine PCIA after Cesarean delivery. Can J Anaes. 2006; 53: 1200-6.

21. Kiliçaslan A, Tuncer S, Yüceaktaş A, Uyar M, Reisli R. The effects of intravenous paracetamol on postoperative analgesia and tramadol consumption in cesarean operations. Agri 2010; 22: 7-12.

22. Chou D, Abalos E, Gyte GM, Gülmezoglu AM. Paracetamol/acetaminophen (single administration) for perineal pain in the early postpartum period. Cochrane Database Syst Rev 2010; 1: Cd008407.

23. Azam Foroughipour FF, Ghahiri A, Norbakhsh V, Heidari T. The effect of perineal control with hands-on and hand-poised methods on perineal trauma and delivery outcome. J Res Med Sci 2011; 16: 1040-6.
24. Tolia P. Intravenous Paracetamol Infusion Versus Intramuscular Tramadol As An Intrapartum Analgesic. Int J Current Adv Res 2018; 07(6): 13875-878.

25. Neha Garg, Vanitha VG. A Randomized Controlled Trial of Intravenous Paracetamol and Intravenous Tramadol for Labour Analgesia. Obstet Gynecol Res 2019; 2(2): 3-13.

26. Abinaya A, Latha K, Jayashree V. Comparative study between intravenous paracetamol and intramuscular tramadol as labour analgesia. International Journal Of Current Medical And Pharmaceutical Research 2017; 3(10): 2491-6. 